\title{
Barriers to the Growth of Small Firms in Pakistan: A Qualitative Assessment of Selected Light Engineering Industries
}

\author{
Nazish Afraz ${ }^{*}$, Syed Turab Hussain ${ }^{* *}$, and Usman Khan ${ }^{* * *}$
}

\begin{abstract}
This article identifies constraints and barriers to growth for small firms in Pakistan, a survey of the existing literature and through in-depth interviews with a sub-sample of firms in two important SME sectors, that is electrical fans and sporting goods. Policy recommendations for the SME sector include addressing problems in contract enforcement (such through alternative dispute settlement mechanisms), promoting $R \mathcal{E} D$ through linkages with academia locally and research institutions globally, simplifying of the tax regime to encourage transparency, resolving the energy crisis and rationalize power tariffs, increasing the availability of credit to SMEs (allowing alternative forms of collateral). In addition, more detailed recommendations specific to the fan and sporting goods sectors are also offered.
\end{abstract}

Keywords: Pakistan, SMEs, light engineering, constraints, electrical fans, sporting goods.

JEL classification: L10, L60.

\section{Introduction}

This study explores the impediments faced by Pakistan's small and medium enterprise (SME) sector. SMEs in Pakistan constitute 90 percent of all economic establishments, contributing 30 percent to GDP and 25 percent to export earnings. Improvements in the SME sector, therefore, have important repercussions for growth and employment, making the sector a focal point for industrial policy. Pakistan's growth in general and that of the manufacturing sector specifically has remained fairly stagnant in the recent past. Over the period 1960-2012, the country

\footnotetext{
* Adjunct Faculty, Department of Economics, Mushtaq Ahmad Gurmani School of Humanities and Social Sciences, Lahore University of Management Sciences.

** Associate Professor, Department of Economics, Mushtaq Ahmad Gurmani School of Humanities and Social Sciences, Lahore University of Management Sciences.

**** Adjunct Faculty, Department of Economics, Mushtaq Ahmad Gurmani School of Humanities and Social Sciences, Lahore University of Management Sciences.
} 
has achieved an annual average GDP growth rate of only 4.47 percent, with the manufacturing sector having grown at around 6.3 percent. However, over the same period, many regional economies grew far more rapidly, with China leading with a phenomenal GDP growth rate of 9.1 percent during the period 1970-2009.

Many studies have attempted to address the question of diminished firm performance and the limited growth of the manufacturing sector in Pakistan. The vast body of literature that exists on the cost of doing business in Pakistan talks about the stagnation of the manufacturing sector, low levels of productivity, and stunted firm growth. Taking a broader approach, the literature explains how different factors-the shortage and high cost of energy, corruption, macroeconomic instability, the limited availability of skilled labor, credit market failures, weak institutions, infrastructural constraints, and inadequate business management and strategy-have, over the years, inhibited the growth of Pakistani firms.

This study synthesizes the literature explaining key barriers to firm growth and augments it with more insightful evidence built from primary information from two pilot industrial sectors. The unstructured, more detailed format of our interviews with stakeholders has allowed us to complement the aggregated level of analysis provided by standard cost-of-business studies. While these typically identify factors that are common to all businesses operating in a sector, our case studies allow us to corroborate and provide detail on these factors. In addition, the case studies allow us to delve deeper by identifying specific characteristics that enable some firms to succeed despite the industry-level barriers common to all firms within the industry.

We have developed case studies on the fan and sporting goods industries, both of which fall in the light engineering sector. The two industries were selected based on the importance of the light engineering sector in terms of value added and employment generation. Within these two industries, we cover a spectrum of firm types, from those reliant solely on export markets to those that supply only the local market. This diversity enables insights into the nature and size of the business. While the external validity of the analysis is limited by the small sample size, we are able to identify areas that would benefit from further research and possible policy interventions.

Section 2 describes the methodology employed. Section 3 identifies the main barriers to firm growth reported by the literature. Sections 4 and 5 discuss the case studies in light of earlier research. 
Finally, Section 6 explores the potential for further research and suggests areas on which policymakers could focus to help improve firm productivity in the sectors studied.

\section{Methodology and Sample}

Much of the research on barriers to the growth of small firms is based on cross-sectional surveys that present owners/managers with a list of barriers and a scale on which to rate the applicability of each barrier to their own firm. However, this limits the depth of analysis considerably. First, it is based on perception, which may not match experience. Second, it provides limited policy implications because it falls short of identifying the specific parts of the problematic process.

Keeping this in mind, our approach was to conduct detailed semistructured interviews with a small representative sample of firms in the light engineering sectors. This has allowed greater depth of analysis, complementing the less detailed, but large, cross-sectional studies already available. We have focused on the fan and sporting goods sectors because of the variation they provide: the sporting goods sector is forwardlooking, highly enterprising, and export-oriented while the fan manufacturing sector is largely inward-looking and appears to be trapped in a cycle of low quality and low profitability.

Twelve firms were chosen in each sector such that we had a variation in growth paths. We used existing data on the population of firms to identify the distribution of firms within each sector. For firms in the fan industry, we used a dataset of 125 firms representing 70 percent of the sector. Using this distribution, a purposive sample was selected such that we had as adequate a representation as could be managed within the limitations of a small sample. Firms that responded positively were then interviewed. For sporting goods, we held a focus group discussion at the office of the sporting goods association in Sialkot; with their help, we selected firms (out of a total of 450) that were suited to the applied methodology.

We interviewed at least one of the top few players in the market to examine how the obstacles to growth were circumvented and what determined high growth in that sector. In addition, we interviewed firms that appeared to be struggling to gauge the most severe barriers to growth. The remaining sample comprised firms that lay in between, for example, those that appeared to be on the cusp of breaking into export markets. This allowed us to establish which characteristics allow some 
firms to grow despite the barriers they face, and to compare them to firms that had managed to survive but had experienced more limited growth.

The interviews were open-ended and the firms were directed to lead the discussion by suggesting which barriers they considered most important. We did not give them a list from which to choose (as other cross-sectional surveys have done) since we did not want to influence their responses. In addition, we spoke to the firms not just about their own experience, but also about their perception of the industry and performance of other firms in the sector. We also sought their opinions on issues flagged by other interviewees in order to corroborate the information and obtain a more accurate and unbiased understanding of the industry. Using this iterative strategy, we were able to minimize the influence of idiosyncratic perceptions, giving more importance to opinions and perceptions that were unanimous. However, given the small sample, we did not discard conflicting views, but have presented them as areas that could benefit from further inquiry.

\section{The Barriers to Firm Growth}

In this section, we make use of several recent surveys that have explored the constraints to industry in Pakistan. A useful starting point is the World Bank's Enterprise Survey, which is administered to a representative sample of private nonagricultural firms across a host of countries. The survey aims to assess and track changes in the business environment by collecting a wide range of qualitative and quantitative data, including perceptions of obstacles to doing business across a range of factors: infrastructure, trade, finance, regulations, taxes and business licensing, corruption, crime and informality, finance, innovation, and labor.

Two measures collected by the Enterprise Survey are of particular interest for our purposes: the "top obstacle" to doing business identified by the sample firms and the identification of a factor as a "major constraint." For the former, firms are presented with a list of 15 factors of which they select one as the biggest obstacle they face. For the latter, when investigating a particular factor, the firm is asked if it presents a major constraint to daily operations. The Enterprise Survey was last conducted in Pakistan in 2007 and surveyed over 900 firms (see World Bank, 2007).

Other useful reference points are the World Bank Enterprise Analysis Unit and the Investment Climate Assessment (ICA) surveys. The Enterprise Analysis Unit administered the Enterprise Survey questionnaire 
to a group of 385 Pakistani firms in 2007 and again in 2010. The ICA survey collected data on perceptions of the business environment in 2002 and 2007 (see Manes, 2009). Hussain, Khan, Malik, and Faheem (2012) have also used the ICA as a starting point to identify the constraints faced by Pakistani firms specifically in Punjab. Together, the results from these surveys enable one not just to obtain a snapshot of the constraints that are most relevant at a certain point in time, but also to observe trends that facilitate a deeper understanding of the business environment.

The Enterprise Survey compares the top obstacle reported by businesses in Pakistan to those reported by other countries in South Asia in 2007. Electricity appears to be the most critical constraint, followed by corruption and crime, all three of which were considered more severe than in other countries in the region. Other important obstacles identified include access to finance, tax rates, and access to land. These, and other obstacles, are discussed below.

\subsection{Electricity}

Electricity is not just one of the most important hindrances to present-day manufacturing; it is also one that has been growing in importance. In 2002, 39.3 percent of firms ranked electricity as the most severe constraint (Manes, 2009). By 2007, this had increased to 79.6 percent. Yang (2011) also notes an increase in the percentage of firms reporting electricity to be the top obstacle between 2007 and 2010: from 44 to 65 percent. This reflects the increase in the number of power outages experienced per month.

Hussain et al. (2012) report that, as a result of these outages, firms in Punjab lost on average more than 10 percent of their total annual sales. Unscheduled outages disrupt operations more severely and lead to greater wear and tear of machinery, much of which cannot be repaired locally. The authors' pilot survey finds that more than half the firms sampled reported the number of monthly outages as varying between 45 and 100. This is compounded by the shortage of gas, which could otherwise have served as an important alternative source of energy. The survey finds that 45 percent of firms report that gas is unavailable more than four days a week.

Firms have come up with several kinds of coping mechanisms: 73 percent of the firms surveyed use power generators, over 90 percent of which are diesel-run, tripling the cost per unit of power generated. Most 
firms also employ overtime labor through longer working hours. All these measures increase costs by increasing overheads and worker payments.

\subsection{Corruption}

Transparency International's corruption perception index for 2012 ranks Pakistan at 139 out of 176 countries, with a corruption control percentile rank of just 12 percent. 1 Corruption features heavily in all recent surveys on the barriers to doing business in Pakistan. It is the second most important constraint identified by the Enterprise Survey. The ICA confirms that corruption is a severe constraint, with 56.7 percent of firms ranking it a major obstacle in 2007: an increase from 40.3 percent in 2002 (Manes, 2009). However, the World Bank Enterprise Unit surveys report a decrease over three years, from 27 percent in 2007 to 14 percent in 2010.

Hussain et al. (2012) find that more than a third of the firms they have surveyed identify corruption in their top three constraints. The most common form of corruption reported is the inconsistent interpretation and application of regulations and policies across the government departments relevant to manufacturing: tax, labor, and licensing. Their survey indicates that firms see the process of implementing regulations as deliberately complicated and extractive-one that facilitates rent seeking by government officials. Most firms report having to make informal payments to government officials in order to get things done, with labor and tax inspections identified as the most corrupt processes.

Although fewer firms in Pakistan are inspected relative to comparator countries, the incidence of bribe payments in both departments is, overall, higher (Manes, 2009). Hussain et al. (2012) calculate that, on average, the industry sector loses three to seven days in resolving a single issue with government officials. Their study confirms that labor inspectors are considered the most corrupt, but electricity officials, too, are apt to threaten firms with suspension of power and incorrect billing unless side payments are made.

\subsection{Crime, Theft, and Disorder}

Crime and the inefficacy of the judicial system is another constraint dominating the surveys analyzed. The percentage of firms reporting crime, theft, and disorder as a major constraint increased from

\footnotetext{
${ }^{1}$ The control of corruption reflects perceptions of the extent to which public power is exercised for private gain. Point estimates range from -2.5 to 2.5, with higher scores indicating less corruption. Pakistan's score is -1.1 on this index.
} 
21.4 percent in 2002 to 32.5 percent in 2007 (Manes, 2009). However, the percentage of firms reporting this as the top obstacle to doing business fell from 8 percent in 2007 to 3 percent in 2010 (World Bank Enterprise Analysis Unit). The ICA surveys reveal that, although crime and security losses are less widespread in Pakistan than in other comparator countries, their intensity is greater.

The World Bank's (2007) survey reveals that less than 20 percent of Pakistani firms believe that the courts function fairly-a proportion half that of other South Asian countries and low-income countries as a whole. The ICA surveys also find that the functioning of the judiciary is a serious obstacle for a third of Pakistani firms compared with a fifth of firms in comparator countries. This is a serious problem because the absence of an effective and fair system of dispute resolution hinders business activity. It also affects long-term investment adversely because the need for investment protection is not fulfilled consistently. As a result of these perceptions of the judicial system, only 5 percent of Pakistani firms chose to settle their disputes in court in 2007-a 40 percent decrease since 2002.

\subsection{Access to Finance}

The perception of access to finance, while remaining an important obstacle to doing business, has seen recent improvements. In 2007, 17.6 percent of firms reported access to finance as a major constraint-an improvement from 38.3 percent in 2002 (Manes, 2009). The World Bank Enterprise Analysis Unit also shows improvements, from 6 percent of firms reporting access to finance as their top obstacle in 2007 to 2 percent in 2010. However, the Milkin capital access index, which scores access to financial capital for entrepreneurs across the world, ranks Pakistan at 74 out of a possible 122 countries in 2009-a reversal in the improvements that were calculated between 2002 and 2006.

The World Bank Enterprise Analysis Unit also reports that less than 15 percent of firms use external financing for working capital compared to over 30 percent in South Asia, which indicates potentially inefficient financial intermediation. In line with this, less than 10 percent of Pakistani firms have bank loans or lines of credit with a bank compared to over 30 percent of firms in South Asia. Hussain et al. (2012) report that this is a more severe obstacle for smaller firms. 


\subsection{Macroeconomic Instability}

Macroeconomic instability has become more important as a barrier to doing business: the percentage of firms to have declared it a major constraint increased from 34.5 percent in 2002 to 56.6 percent in 2007 (Manes, 2009). Hussain et al. (2012) report that 7.9 percent of firms in Lahore identify macroeconomic and political instability as their most serious constraint while almost 46 percent rank it among their top three constraints. Macroeconomic instability is more serious for those firms that depend on imported raw material as the depreciation of the rupee increases their costs of production. Both exchange rate volatility and inflation are seen as impediments to doing business.

\subsection{Political Instability}

Yang (2011) reports that 20 percent of Pakistani firms ranked political instability as their top obstacle to growth in 2010-a fivefold increase from 2007. The ICA surveys also find an increase between 2002 and 2007, from 40.4 percent of firms reporting political instability as a major constraint in 2002 to 46.8 percent in 2007 (Manes, 2009).

\subsection{Inadequate Workforce}

The constraint of an inadequate workforce does not feature heavily in the national surveys we have examined. Yang (2011), for example, reports that the percentage of firms that identified inadequately trained labor as a major constraint fell from 2 percent in 2007 to 1 percent in 2010, with both figures being lower than the global and South Asian averages. The World Bank (2007) also finds that 8.1 percent of Pakistani firms cited the lack of an educated workforce as a major constraint compared to 14.3 percent in South Asia and 26.8 percent globally.

However, Hussain et al. (2012) identify this factor is a key impediment to industrial performance in Punjab, listing it among their top five constraints for the region. Apart from textiles and leather, where it is seen as a major obstacle, most sectors view labor quality as a moderate constraint. The authors find that low levels of education, both in terms of the quality of education and number of schooling years, impede skills development. Low levels of basic literacy mean that written instructions are harder to follow, even at a more basic level of manufacturing. It also means that firms have to offer training programs in-house, which raises their costs of production. 
The constraints discussed above have been identified in recent perceptions-based surveys. This is an important complement to our own fieldwork because the surveys were larger and it is, therefore, easier to identify these constraints as universal enough to have policy implications. However, there are some serious limitations. The data quoted above highlight the fickle nature of using variables such as the "top constraint to doing business," which is identified as a single variable that is, at that time, the most problematic for the firm being surveyed. It does not mean that other factors are, therefore, not important. Electricity, for example, is currently singled out as by far the most important constraint, overshadowing other constraints that affect the long-term viability and growth of firms.

With this in mind, our fieldwork aims to discuss the lifespan of the firm retrospectively, identifying not just constraints that are relevant today, but also those that have influenced the growth history of the firms in the sectors studied and of the industry as a whole. We intend to take a longer-term view of barriers to growth and to explore the specific features of certain firms that make them more resilient to obstacles than others.

\section{The Fan Industry}

Fan manufacturing is a light engineering industry and one of Pakistan's older industries (existing at the time of independence). Here, we describe the sector and examine its constraints to growth.

\subsection{Overview}

The fan industry is clustered in four major cities: Gujrat, Gujranwala, Lahore, and Karachi. However, 98 percent of the country's production is centered in Gujrat and Gujranwala. The location of this cluster appears to have been rather arbitrary, born of historic path dependencies. However, with the development of a vibrant cluster over the years, firms have benefitted from external economies such as sufficient access to raw material with over 700 vendors operating in the area.

The fan cluster has grown significantly in economic importance over the 2000s, experiencing an annual average growth rate of 17 percent since 1999. Currently, production equals approximately 10 million fans per year and accounts for PRs 18 billion in sales $(0.27$ percent of the national GDP). The fan industry feeds on a wide range of supporting industries, including plastic, aluminum casting, and steel. The potential 
reverberations in the economy are, therefore, far greater than what the figure above represents.

Furthermore, the cluster provides direct employment to 35,000 workers in the area and indirect employment to roughly four times this figure. It also contributes 0.2 percent to Pakistan's total exports. The sector's performance in the export market has picked up recently, with foreign exchange earnings consistently on the rise. In recent years, Pakistan's exports have reached US\$ 40 million, increasing its share of world fan exports to over 1 percent. However, the number of fans exported has fallen over the last two years.

The fan industry comprises roughly 450 medium, small, and micro-enterprises. This structure is sharply fragmented with five or six of the largest companies responsible for 70 percent of the total industrial sales. They are classified as large-scale manufacturing units, characterized by higher levels of investment and modern technology. Most of these firms are individual proprietorships and small partnerships, over 90 percent of which are formally registered. Output consists of a diverse production mix with ceiling fans representing 60 percent of total production and pedestal fans and other categories accounting for another 30 and 10 percent, respectively. Overall, the fan cluster represents a significantly mature and well-established industry: about 72 percent of its firms are 10 years or older. There is also a high correlation (0.9) between firm age and sales, reflecting the sector's stability in terms of solvency.

\subsection{Constraints}

In this section, we discuss which features have prevented the industry from reaching its full growth potential. Previous research on the fan industry has flagged barriers to growth such as low levels of investment in research and development (R\&D), the myopic entrepreneurial mindset of cluster firms, problems of seasonal production, quality constraints, and limited access to viable credit (Munir \& Khan, 2011). Using our case study approach, we were able to explore these barriers in greater depth and isolate some of their root causes. In addition, we find that institutional features, poor factor markets, and management issues all contribute to an environment that ultimately impedes growth. We also examine what make these constraints so hard to overcome at the individual firm level. 


\subsubsection{Standardization}

Quality constraints have restricted the expansion of the fan industry and limited its potential for growth, particularly in the international market. Exports over the last two years have fallen because of the sale of substandard products, which has been a severe setback for the industry. As an electrical product, fans have to comply with certain minimum electricity safety and performance requirements and this compliance is key to maintaining a successful business. However, the firms in Pakistan's fan industry do not have a standard-quality product and do not even use standardized inputs. For example, each firm uses parts that are not necessarily substitutable in other fans. The result is a market flooded with unregulated parts and products. Larger firms are able to circumvent the problem of quality assurance by exporting directly and having their products certified privately by international laboratories their clients trust. However, for the large majority of small firms, standardization remains an insurmountable problem.

Munir and Khan (2011) find that the key reasons for low standardization and compliance are lack of capital and slack enforcement of standards in local markets. Probing this further, we have found that the lack of unity among firms and the pressure to compete on price remain the most severe impediments to standardization. A case in point is the recent failure of a large order sent jointly by several firms to Iraq. The trader who received the order then auctioned it off to several small firms, each of which was to deliver an unbranded product to the trader. There was pressure to compete on price and no repercussions for individual companies sending poor-quality fans. A poor-quality shipment was dispatched with the result that the reputation of Pakistani fans in Iraq was ruined and the demand shifted to China and India.

Several firms mentioned this recent failure, which highlights the difficulties small firms face in reaching international markets. They are too small to export directly and have to rely on traders. The traders have no incentive to develop a brand reputation and to ensure that quality standards are met. The firms themselves are fragmented and operate in an intensely competitive environment, which prevents them from uniting in the domestic market. They cannot export without certification, but without an export order already in place they find it difficult to justify the expenditure on private foreign certification (which costs approximately PRs 80,000 per product line). 
While the Pakistan Council of Scientific and Industrial Research exists to address these issues, the industry perceives it as a corrupt body that is prepared to certify substandard products based on payments rather than laboratory tests. These firms are aware that standardization is now a prerequisite to exporting successfully; finding a way to achieve these standards jointly was, therefore, at the forefront of the agenda of the small firms we interviewed.

\subsubsection{Access to International Markets}

The large majority of small fan manufacturers target only the local market. Larger firms export a small proportion of their output via traders, but are not always even aware of the final destination of their product or of the modifications it will undergo before being shipped. Only the largest few firms export a significant portion of their production directly. Barriers to entry in the domestic market are low, with the result that the market is saturated with small firms operating on thin profit margins. The firms we interviewed were all well aware that tapping into foreign markets was the only way to break out of the incremental growth path that comes from expanding one machine at a time to make fans for domestic markets. However, they appear to be trapped in a cycle of low capability, poor quality, and poor investment because of which they cannot break into the export market.

Their low capacity and capability means that, if they were to try to manufacture fans for export, they would need to divert all their resources toward it, tying up capital in purchasing, for example, electric sheet instead of recycling scrap metal as they do for local markets. However, the export business is risky and if that order did not result in a sustained demand for the new high-quality product, they would also lose their established local market-a risk that the smaller firms are not prepared to take.

Small firms also lack the know-how and human resources needed to process the paperwork involved and handle government departments and banks. For some firms, this discourages them from even attempting to export directly. For others, the lack of information means that the chances of failure are higher (see Box 1 below). Larger firms usually employ someone exclusively to deal with these requirements. They are also able to undercut the orders obtained by smaller firms, which acts as another major disincentive for the small firm to attempt to export. For smaller firms, therefore, risk aversion, driven by low capacity and low profitability, is the biggest impediment to venturing into foreign markets. 


\subsubsection{Management and Succession Planning}

Many of the small firms struggle with management issues. The firm's chief executive officer (CEO) typically manages the business singlehandedly, delegating very little to other staff. Some management is sometimes shared with other relatives successfully, but this is not always the case. The firm's ability to grow is, therefore, constrained by the capacity of the individual. Several factors contribute to this practice: low profit margins, the inability to retain staff, low trust, and poor contract enforcement. Low profit margins mean that firms simply cannot afford to hire professional accountants and managers. The scale of operations is too low to justify it and the lack of vision that comes from the absence of professionals further constrains growth and output.

\section{Box 1: The case of Golden Star}

Malik Zulfiqar Anwar's motto of "making the impossible possible" is well suited to the history of his firm. He started off as an uneducated worker at Famous Fans. In 1960, he purchased a broken machine from his employer, using PRs 4,000 that he had received as a bonus, to make a down payment. In the evenings, he started to manufacture fans, using the repaired machine to perform two different operations by changing the end tool. In 1986/87, Anwar established Gold Star as a partnership. He sold the small number of family assets he had-his motorcycle and his wife's jewelry-and invested all the money into his fledgling business. For a long time, neither partner drew a salary and worked around the clock to make the firm a success. By 2000, Gold Star was producing 36,000 fans a year.

Shortly afterward, they faced a series of personal setbacks in which the partnership split and the brand went to his partner. However, in 2001, Anwar restarted his business as Golden Star, producing 18,000 fans with two machines. As before, he clawed back all his profits into production. His determination to succeed was so strong that he would personally market his fans door-to-door, competing so heavily on price that he was making barely PRs 50 per fan. With the brand name established, the firm's production volume picked up and business stabilized.

His next step was to attempt exporting his product line. Not being educated, he had no idea how to obtain the required licenses and certifications. He approached the Pakistan Electric Fan Manufacturers Association (PEFMA) and a leading fan manufacturer who was already exporting, but to no avail. Eventually, he dispatched a 20-foot container to Dubai without the necessary paperwork. Although the shipment was held and his payment stalled, he dispatched another 40-foot container to Jeddah. That, too, ended up in Riyadh instead and payments for both containers were received three years after the containers had been sent. Slowly, however, he learned how to export-the 
hard way. Today, his exports stand at PRs 120 million; he now operates two
factories and has several small, diversified businesses on the side.
By his own evaluation, Anwar has succeeded. Although his firm is still small,
he has made some successful inroads into foreign markets and can see the
potential for growth ahead. However, his case shows how every step of the
journey was fraught with obstacles and illustrates how frustrating and
discouraging the effort to grow beyond the domestic market can be when
external support is missing.

These firms appear to be stuck in a vicious cycle of low profits and low investment in firm capabilities. Many felt that larger firms succeeded because they could afford to pay their professional staff better. However, even these large salaries are not enough to retain high-end professionals in Gujrat. The fact that it is a small city means that there is a paucity of educated locals who can be hired. Professionals hired from outside Gujrat do not consider their engagement a long-term option as they do not wish to live in a small city.

In addition, poor contract enforcement and weak law and order mean that pilferage, deceit, and defection to competitors are common-a problem faced by small and large manufacturers alike. Firms may attempt recovery at a personal level, but do not involve the courts or the police, perceiving that the exercise is almost guaranteed to be futile. As a result, the CEO retains all information and authority for fear of leaking confidential information.

As a result of the lack of professional management, the success of a firm depends heavily on the CEO's vision and management skills, the lack of which has caused even large and very successful firms to fail, for example, while transitioning between generations. There are several examples of firm failure due to poor management, one of which is National Fans. Despite its advanced manufacturing facility and status as a market leader at one time, the firm had to shut down because its new generation of management failed to run the firm well. One of our interviewees, the CEO of a successful enterprise, claimed that the failure rate in transitioning from one generation to the next is probably twice that in other countries.

Some firms are able to circumvent this problem by dividing various roles successfully between brothers and/or children. Different people may be assigned, for example, to manage supplies, exports, and operations. This allows them to specialize and complement each other and reach a higher growth path than could be achieved by one person alone. On the other 
hand, we found an equal number of examples where the joint running of a firm by family members had led to its demise. In such cases, lack of unity and trust among the family members operating the business had led to the accumulation of personal wealth rather than investments in the business. Eventually, both the firms and families had collapsed.

The market is rife with such examples of inefficiencies arising out of weak succession planning, and this is cited as one of the most important reasons for firm failure in the industry. Other examples include fragmentation into small units-each replicating the existing business model-rather than the consolidation and specialization that could come from pooling resources and human capital.

\subsubsection{RED}

Lack of investment in R\&D via a strong support sector emerges as one of the top constraints impeding the industry's competitiveness. Munir and Khan (2011) undertake a value chain and productivity analysis, which reveals that the sector faces several supply-side constraints and weaknesses in value addition. Specifically, the industry typically adds around 20 percent in value, which amounts to a mere PRs 450 per fan.

This low level of productivity is a result of the lack of modern technology and weak production process flow management. Around 80 percent of the costs are material costs, which can easily be circumvented by developing new materials that are cost-effective. For instance, the development of alternative materials has enabled the Chinese industry to reduce their production costs significantly. However, the Pakistani fan cluster suffers from weak academia-industry linkages and low investment in R\&D. The techniques used by the local industry are now outdated: 42 percent of firms still use technology installed over 10 years ago. This severely constrains them from realizing significant opportunities for value addition.

It also precludes the development of a strong and viable ancillary and support sector for the industry. Specifically, the industry (and any support linked to it) has no capacity for working on product design, development, quality standards, and marketing. Manufacturers also want strongly to increase the quality of their vendors since 92 percent of the firms outsource some of their production processes.

This technological setback has contributed further to the lack of support institutions and common services technology institutions. The 
Fan Development Institute was introduced into the cluster to help firms make a smooth transition from manufacturing units into a cluster with the capacity for internal innovation. However, it has failed to achieve its objectives so far. To make matters worse, firms generally lack information regarding sources of external support for increasing competitiveness. Almost all the firms we surveyed were unaware of any support activity being provided in the cluster.

Alongside limited investment in technology and cutting-edge research, the industry's myopic entrepreneurial mindset has left the cluster far behind in realizing the true economies of scale that result from agglomeration. According to Porter's diamond model, the way that firms are organized, created, and managed within a cluster has a significant bearing on its national competitive advantage. This domestic rivalry is also important in stimulating pressure to innovate, thus determining the development of successful industries in a cluster.

Our case studies reveal that the most important reasons for low investment in $R \& D$ are the low level of education and professional skills, the narrow profit margins on which many firms operate, and the low level of trust and cooperation within the sector. Poor levels of education and professional skills limit how firms visualize growth in the sector. This has meant that most small firms know only one way to grow: increasing production and sales by scaling up their existing infrastructure. In addition, since these firms rely primarily on their own accumulated funds to scale up, they usually grow one machine at a time, with little room for process innovation or large-scale overhauls of the production technology.

There also appears to be little scope for collaborative research as the culture in which the fan industry conducts its business is one of secrecy, suspicion, and market warfare. The underlying lack of trust means that firms do not wish to contribute to programs that do not benefit them per se as they believe their individual efforts will benefit the entire sector at a cost to themselves. The option of diverting resources toward an investment that will not improve their own competitive edge over other domestic players is not considered an attractive one. This precludes peer group learning, as a result of which the industry is dominated by small firms that do not benefit from economies of scale.

The larger firms do, however, engage in some R\&D: Royal Fans, for example, is in the process of developing a fan that is not sensitive to power fluctuations while running on a low-quality UPS. However, even among the largest firms, most R\&D takes the shape of reverse engineering. 


\subsubsection{Seasonal Production}

The issue of seasonal production is also a critical hindrance to the growth of the industry. Most firms perceive their capacity utilization as being in the region of about 80 percent. However, this is an inadequate indicator of demand as the industry operates near full production capacity only during the first five months of the year. Off-season, factories suffer from a lack of capital to maintain production; during the season, they have excess supply capacity. This seasonal production not only impedes investment, but also drains out skilled workers from the industry. As a result, production is far below its potential since the cyclical labor is not willing to invest in training and human capital development for an industry that provides employment only five months of the year.

This, coupled with inadequate training facilities, has further constrained human resource availability: over 30 percent of the firms we surveyed said they found it difficult to procure a skilled workforce. This is corroborated by the lack of management capacity and poorly documented production and monitoring activity, which makes it difficult to track performance. Seasonal demand and production also complicate the accounting process as prices and costs both vary over the year. The basic accounting systems in place among small firms cannot handle costing and pricing exercises effectively under these circumstances.

\subsubsection{Factor Markets}

Labor. Labor that is reasonably suited to fan manufacturing is easily available in Gujrat, where it is a home industry. However, skilled and educated labor is harder to find and retain. This impedes the adoption of more complicated machinery. Most small firms' operations focus on basic manufacturing techniques and machinery. Additionally, pilferage and poor law enforcement lead to an erosion of trust.

Credit. Like all SMEs, the lack of access to viable credit is also a critical issue for the fan industry-a problem that is exacerbated by the paucity of reliable financial data. A survey conducted by the Asian Development Bank suggests that, in Pakistan, only 6 percent of fixed investment finance for SMEs comes from commercial banks and development finance institutions (Bari, Cheema, and Haque, 2005). The problem of access to credit is more acute for smaller firms in the fan cluster, which are virtually shut out from access to bank credit. About 85 percent of the firms in the cluster reported "self-financing" as their primary source of funding (Munir \& Khan, 2011). 
This limited availability of viable bank credit stems from the capacity issues that plague firms and banks alike. Firms suffer from typical SME information asymmetries and limited capacity to provide reliable financial data. Most of their financial transactions are recorded informally and almost 70 percent do not use audited financial statements. This creates a classic case of information asymmetries and moral hazard since banks cannot differentiate between high-quality and low-quality projects or ascertain whether the funds given to the firms will be appropriately used. This was verified by our own interviews, which yielded examples of firms that had obtained bank loans for a planned default or for purposes other than those for which the loan had been sanctioned.

To make matters worse, SMEs face a more uncertain competitive environment and are less equipped to deal with economic adversity and risks. To circumvent this problem, banks require the financing to be collateralized, with the collateral often exceeding 100 percent of the loan. This further bars firms' access to credit since they do not possess assets that can be collateralized.

Details from the case studies have enabled us to tease out additional demand-side issues that affect bank-financed investment. Most of the firms we interviewed said they used banks for ordinary transactions and their overdraft facility for working capital, but still preferred using "market credit" 2 even though they recognized that this was an expensive way to finance their operations, given that prices were approximately 10 percent higher for supplies purchased on credit.

Market credit is not just expensive, but it is also a fragile and not necessarily dependable system. Credit cycles of different duration and involving several players exist, increasing the codependence of the firms. Default by a single firm can have a domino effect so severe that several firms have been reported to go out of business as a result. Market credit also complicates the accounting process. The multi-party overlapping system of credit was cited as a cause of failure where some firms had misinterpreted the spreadsheet balance as profit. This had led them to sell below cost and eventually collapse as the credit bubble became unsustainable.

Another reason given for the low demand for credit is that, for many small firms, the return to the capital invested is not higher than the bank rates and charges involved. It is not, therefore, worth their while to

\footnotetext{
${ }^{2}$ Market credit is the practice of buying raw material on credit. Repayment is required only once the final product has been sold, thereby creating a chain of credit in the market.
} 
borrow from a bank to invest in their business. In addition, firms tend to dislike the formality and rigidity of dealing with a bank. Some respondents claimed that they simply did not want to owe that kind of money. Others had had bad experiences with bank loans and found the repayment schedule too burdensome.

From this, it appears that commercial banks do not serve the requirements of SMEs in the fan cluster. There has never been any pressure on commercial banks to extend long-term credit to the SME sector and, as a result, commercial lending remains too expensive, inflexible, and complicated for these firms.

Capital. All the smaller firms in the sample work with recycled material and machinery. Typically, used machinery is purchased in the second-hand market at Daroga, where it arrives as factories around the world discard it as obsolete or shut down operations. The firms purchase these machines, repair them, and make adjustments locally. This way, the machines typically cost less than half the price of a new machine. However, these machines also have a much smaller capacity than those employed by larger factories. For firms serving the local market, this machinery and installed capacity is sufficient, but it also prevents them from bidding for foreign orders independently. They are well aware that their own capacity is insufficient and that they lack the unity and standardization to work together.

\subsubsection{Branding}

The establishment of a brand name is an important factor in the success of large firms in the fan industry. The first few market entrants started with substantially more capital and were able to develop a brand name associated with a high-quality product. These firms are now able to charge a premium for their products and, consequently, have a greater outlay on advertising and maintaining their brand name.

Smaller firms may be able to produce high-quality fans, but cannot obtain the required price. This acts as a disincentive to invest in improved quality. Such firms may also engage in small-scale, low-end marketing, but with so many small firms competing with each other using similar marketing strategies, it is difficult for one firm to stand out. Here, again, intense price competition and low profit margins emerge as the underlying factors behind firms' inability to establish a high-quality product with an established brand name. 


\subsubsection{Institutional Support}

Firms in the fan industry operate in an environment that provides little institutional support: they cannot rely on the courts and law enforcement agencies, have little in the way of consistent support from the research and other support institutions set up specifically to assist them, and face corrupt and inefficient government departments. This section explains how these institutional features compel firms to remain small.

The courts and law enforcement. Firms can face several legal issues, including theft, outright robbery, and breaches of contract. However, they unanimously reported having to absorb and accept such losses or to deal with such cases in their limited personal capacity. Since it is common knowledge that the courts and law enforcement agencies are not effective, the repercussions of reneging on a contract or stealing from an employer are low; the practice is thus rampant. Although much of the pilferage is low-level and more of an irritant than a major obstacle, the underlying trust issues it creates are much more serious. Firms feel they cannot effectively delegate authority and control to their labor, which is a major barrier to their ability to grow.

PEFMA. PEFMA was intended to serve as a platform from which fan manufacturers could address the issues they faced jointly; it could, potentially, have paved the way to greater standardization, quality control, and export opportunities. However, PEFMA remains a controversial organization. Originally, it was created and managed by the largest few companies and some firms claim that, at that time, the benefits of any orders, inquiries, and information that came via PEFMA were not circulated widely enough, thus disproportionately benefitting the larger firms. For example, when the Small and Medium Enterprises Development Authority (SMEDA) held workshops on brand development and media planning (organized via PEFMA), smaller firms were not informed. The larger firms were, therefore, able to develop an even greater competitive edge over the small firms. Although the association is now managed by the smaller firms, it has since lost the main benefits it had purported to deliver, possibly due to lack of connections and knowledge.

Currently, most firms agree that PEFMA is a fair, equalopportunities organization. Even the smallest firms reported attending workshops it had organized. The support it provides is, however, limited and only firms that have the requisite ability and aptitude are liable to benefit. 
Government departments. Most respondents reported that tax and labor department officers actively encouraged under-reporting income and employment, going so far as to suggest what kind of fictitious numbers would mutually suit the officer and the firm. In the short run, this might appear to benefit the firms as it allows them to evade tax, but in the long run it is extremely harmful-a fact that most firms seem to recognize. It prevents them from keeping a transparent set of financial records, which would allow them to benefit from accurate accounting and access to formal credit. It also leaves open an avenue for blackmail and extortion, the fear of which keeps them in the grey.

All firms said they would like to be clean, but for an individual firm, the barriers to this are insurmountable. It renders them uncompetitive if other firms continue the practice of under-reporting and it also means that all prior accounts might be questioned, which would expose the firm to more legal inquiry. This fear of being checked keeps many firms small so that they can stay under the radar of enforcement agencies.

There is also the view that larger firms have an edge in handling government departments: they have better established contacts through which they can have their work cleared easily, for example, at customs. Other benefits include being able to hire or allocate someone exclusively for lobbying and handling government departments and bureaucratic procedures-something that is outside the scope of the smaller firms. Some small firms also claimed that effective lobbying by the large firms meant they were able to have policies approved at the Federal Board of Revenue that benefitted them (large firms), such as income tax commissions, which are the same amount for everyone, regardless of size. One respondent went so far as to claim that some institutional officers were on the payroll of certain companies and sought to actively create obstacles and delays in processing the applications of competing firms.

The lack of formality in the supply chain is also a problem. Even though some firms are registered for sales tax, the material they purchase has no proof of sales tax having been paid because all receipts from suppliers are informal. These suppliers provide proper receipts only to the large firms, with the result that the latter can obtain tax rebates while the smaller firms cannot. 


\subsubsection{Gas and Electricity}

Energy shortages are particularly severe for smaller firms. While all firms said they had made alternative arrangements, low power supplies tend to hit small firms the hardest, given their already low margins. The cost of alternative fuel can be debilitating. We were told that natural gas was available for the first 20 days of each month while furnace oil had to be used as a substitute for the next ten days. The cost of furnace oil over those ten days easily exceeds a firm's expenditure on gas for the whole month. Furnaces need a large volume of gas to reach the requisite temperature. As the gas pressure falls, the furnaces begin to cool. Both gas availability and consistent pressure are, therefore, issues that firms must contend with on a regular basis.

Electricity, too, poses a constraint: although the firms were all equipped with a UPS or generator, it had raised their cost of production. Furthermore, unscheduled and prolonged power outages cannot be sustained, causing problems even for the large firms.

\subsection{Conclusion}

In summary, the smaller firms in the fan industry seem to be trapped in a vicious cycle perpetuated by their low profit margins. This has led to low investment in professional management, brand establishment, installed capacity, and certification. Without these investments, they cannot tap into the higher-margin export market. However, without the revenue boost of exports, the firms cannot generate enough profit locally as they operate in an intensely competitive domestic market where competition is on price rather than quality. The institutional features of the environment in which they operate also perpetuate this cycle by remaining more accessible to larger firms and creating disincentives to becoming transparent.

Although the fan cluster in Pakistan has emerged as a vibrant agglomeration promoting the growth of incumbent firms and attracting new entrants because of low barriers to entry, there is still considerable potential for creating economic value, which has not been exploited for the reasons discussed above. The scale of production remains small, with the average output of a median-size factory being 500 fans per day (compared to 35,000 fans for a factory of comparable size in China). There is a need to move away from these closed ownership patterns toward greater informal and formal collaboration within the cluster. 


\section{The Sporting Goods Industry}

The sporting goods industry in Pakistan is clustered mainly around the city of Sialkot, which accounts for nearly 95 percent of the industry's total production. The location of this cluster is largely a result of agglomeration economies, Sialkot having been a center of excellence for the production of sporting goods for more than 100 years. This is attributed to the availability of skilled artisans and entrepreneurs in the city and its favorable indicators for literacy, health, electricity, and water facilities. In addition, Sialkot benefits from the availability of a basic infrastructure for industry, including a dry port and an international airport, which serves as an export hub for manufactured goods.

\subsection{Overview}

Sporting goods producers in Sialkot are predominantly SMEs comprising over 360 formal and over 10,000 informal units. The main sporting goods produced can be divided into five categories: (i) articles and equipment for physical exercise, gymnastics, and athletics; (ii) articles and equipment for fishing; (iii) sports gloves; (iv) articles and accessories for billiards; and (v) articles for funfair games. Among these, articles for gymnastics and athletics and articles for funfair games have been the key drivers of the sector's growth in the world. Moreover, the country is considered a leading manufacturer of footballs, cricket balls, hockey sticks, and cricket bats-products that enjoy global market recognition.

As a result of this reputation, the Sialkot cluster has successfully established linkages with major international brands that source a large portion of their supplies of sporting goods from the city. The sporting goods industry has, therefore, been an integral part of Pakistan's economy, providing employment to 300,000-350,000 skilled and unskilled laborers. The sector also represents roughly 1.42 percent of the country's total export base.

Despite its current and potential importance to Pakistan's economy, the sector remains mired in difficulties due to the limited opportunities for growth. For instance, most of the companies in Sialkot fall under the category of commercial exporters, which have minimal staff and operate with a very short-term orientation, in turn facing high failure rates. Additionally, the recent energy shortages have affected the sector's competitiveness adversely and seriously impeded its overall growth. 
Having failed to perform to its capacity, the industry now faces a decline in its share of sporting goods exports. Although Pakistan's sports goods have enjoyed a sound reputation worldwide, the industry has failed to convert this into a sustainable and growing share of the global market: Pakistan accounts for less than 1 percent of the total worldwide sale of sporting goods. While its global exports increased more than 100 percent from US\$ 7.5 billion in 1999 to US\$ 18 billion in 2009 (Competitiveness Support Fund, 2010), sporting goods exports have remained stagnant and currently stand at US\$256 million. This is evident in the stark difference between the average market share of China's sporting good exports (32.5 percent) and that of Pakistan (1.37 percent).

Part of this less-than-satisfactory performance can be attributed to the effects of the financial crisis in the US, which had an adverse impact on Pakistan's trade since the sporting goods industry is largely consumerdriven, its major importers being the US, the UK, Germany, and France. However, a greater cause for concern is that, in recent years, not only has Pakistan's share of sporting goods exports declined, the sector has also registered the highest negative annual growth of exports relative to its competitors. This is true for three of the five sporting goods categories: articles for gymnastics and athletics, articles and equipment for fishing, and articles for funfair games.

\subsection{Constraints}

The following analysis of the sporting goods sector identifies some critical issues at the level of the firm and the industry that constrain both firm growth and overall industry development.

\subsubsection{Credit Market}

In the interviews we conducted of 12 sporting goods firms, which ranged from small and medium to large, we found that SMEs did not borrow from the formal credit market, i.e., commercial banks. Borrowing from commercial banks is generally limited to letters of credit, overdrafts, and short-term working capital. None of the SMEs interviewed had ever resorted to long-term financing for capital investment purposes.

The main reason they cited was the high interest rate charged by commercial banks, which, according to some firms, was greater than their expected return from business. There is also too much uncertainty inherent in the sector, especially for smaller enterprises, most of which rely entirely on foreign buyers, which means that a couple of defaults on 
large shipments can potentially result in firm closure. Hence, factory owners are generally risk-averse and tend to diversify investments in assets that are perceived to be more secure.

The recent energy shortages, weak law and order situation, increasing security concerns, and general uncertainty also explain why firms are reluctant to consider formal borrowing or even to use retained earnings for investment in their own business. Instead, money is channeled into "safe" investments such as land and gold.

This behavior has a perverse outcome: small firms that make a profit and are more risk-averse do not invest and grow, but choose to diversify out of the sector instead; this partly explains why many of them remain small. Very few large firms reported having taken recourse to formal long-term financing to set up their factory or plant. Most of them had, however, used retained earnings to increase their plant size or upgrade machinery and technology.

\subsubsection{Entrepreneurship, Management, and Succession Planning}

Sialkot's strength lies in the versatility, dynamism, and enterprising nature of its population. Relatively better educated than the rest of the country and exposed to international markets, potential entrepreneurs start early in life. Their entry into business is via trading: obtaining orders on the Internet is relatively easy as is finding manufacturers to meet the orders. It requires a very low level of initial capital investment and has low barriers to entry otherwise as well. Profits made through trade are most often invested in small-scale manufacturing and export. By the time these young traders get into manufacturing, they have already established a potential international clientele through previous trading relations and contacts. Thus, the general transition in Sialkot is from trading to manufacturing for export. This particular feature makes the emergence of small enterprises easier and more frequent in the cluster.

Although there is no dearth of entrepreneurs in the sporting goods sector, firms' management practices leave something to be desired. Generally, SMEs are managed and run by the owner. This limits expansion beyond a certain point and makes the business highly sensitive and vulnerable to the abilities and decisions of an individual. From our interviews, it was evident that the management and production activity of most firms was ill organized. Hardly any standard management practices were employed, even in some of the larger units. 
Firms generally lack a well-educated, socially aware professional middle management due to which they tend to lag behind in areas such as efficiency, workforce productivity, and marketing. As a consequence of inefficient management, little to no attention is paid to meeting social standards such as hiring fixed-wage workers or maintaining a good working environment. As these firms grow and start catering to international brands, they begin finding it difficult to adhere to and comply with the social standards imposed by the brands concerned.

For instance, when Silver Star, a leading local manufacturer of inflatable balls, became a supplier for Nike, it was forced to adopt Nike's business model, which included converting piece-rate employees to salaried workers, offering them better incentives, establishing fixed working hours, not allowing people to work from home, and instituting a proper monitoring system. Although there is growing realization that, if local firms are to compete internationally, they must bear the costs incurred in meeting the standards of international brands, efforts to comply remain fairly weak.

However, there are some important exceptions-these are the firms that have established themselves as major suppliers of large international brands. These brands closely monitor the production and management of their international supply chain to ensure that the required quality standards are met. The successful firms are those that have been able to comply with these standards and changed their management style and production methods according to the specified standards of their brand.

None of the SMEs we interviewed were new entrants to the sporting good sector. On average, they were almost 50 years old, most having started as a single establishment, which, over successive generations, had been divided among the family. Similar to other sectors, succession planning is a critical issue and one of the factors differentiating success stories from failures. Sporting goods firms are usually owned by members of one or two families where the head of the family is in charge of running the entire business. In case he or she is incapacitated, there is usually no succession plan in place whatsoever, thereby creating major problems for firm survival.

Those companies that have adopted a more systematic and professional approach to succession-where the younger generation is gradually trained in the business and given room to innovate and change-have been more resilient. Moreover, firms that have established 
export markets and the ability to diversify and differentiate products for the international market have tended to grow in spite of divisions. In such cases, it was rare to find a parent company fragmenting into inefficient smaller units with each facing diseconomies of scale and scope.

\subsubsection{Labor Market Issues}

According to most of the firms we interviewed, a major competitive advantage that Sialkot has over other manufacturing and export hubs across the world is the availability of cheap labor. However, this competitive edge is blunted if we compare the average skill level of Pakistani workers to those of workers in other developing countries. Thus, while it may be that labor in Sialkot is cheap relative to that in China, the former may not be as productive. This lack of human capital is a result of Pakistan's low levels of primary and secondary education and makes it more difficult to train labor. Hence, whereas Pakistan has a large and growing pool of workers, whether this translates into a competitive advantage is questionable, especially since there are few, if any, training facilities or degrees in educational institutions that are geared toward the industry in general and sporting goods in particular.

Firms that invest in new machines and technology may also find that training workers presents a challenge. For firms that supply major brands directly, this is less of a problem-they are required to upgrade and improve their workers' skills and comply with international labor regulations in any case. However, for smaller firms that export indirectly (through buying houses) and have low-skilled workers, investing in training is perceived as a risky and costly activity, especially in the absence of labor contract enforcement. For these firms, low-quality labor becomes a binding constraint to further growth.

Larger enterprises are more likely to face problems retaining highly skilled staff such as engineers, who generally prefer moving to bigger cities such as Lahore or Karachi. Some of these firms have resorted to hiring diploma holders who are trained on the job and are easier to retain.

A key labor-related issue raised by the firms we interviewed was the voluntary signing of International Labour Organization (ILO) regulations by the Government of Pakistan. Interestingly, India and China have not signed these regulations and, hence, buyers do not seek compliance from them. However, exporters from Pakistan are bound to comply with a host of ILO regulations, which increases their cost of production, making them relatively less competitive. 


\subsubsection{Supply of Raw Material and Absence of Ancillary Industry}

A global shift in technology in the sporting goods industry in the 1980s occurred with the introduction of composites in sports rackets and hockey sticks. This change hit the Pakistani industry hard as it was slow to move to composite materials, and many tennis, squash, and badminton racket manufacturers were forced to close down. There has been no domestic investment in composites since and manufacturers have to import all their raw material (paper, lacquer, resin, carbon fiber, and glass fiber). Their complete reliance on imported raw materials makes these firms susceptible to exchange rate shocks, customs duties, and bureaucratic rent seeking. There are also regulatory issues to contend with in the case of carbon fiber imports, which have potential use in the defense industry.

One firm reported that India had allowed exports of carbon fiber to Pakistan, but the Pakistani government had, for its own reasons, not allowed these imports. Although importing raw material from India would be much cheaper, regular instances of delay in releasing shipments at the Wagah border deters firms from doing so. These delays are primarily due to customs procedures and red tape, which can even require negotiations at the highest bureaucratic level for a shipment to be released.

Furthermore, the quality and price of the final exportable product hinges completely on the availability, consistency, and quality of raw materials. Almost 90 percent of the sector's raw materials and inputs are imported from China, Japan, Taiwan, and Europe. As stated above, government policy has failed to encourage any investments in large-scale input industries. The absence of such primary industries as chemical and latex manufacturers and of design houses and quality testing and certification facilities has seriously hampered the sector's overall growth.

\subsubsection{Innovation and Product Diversification: The Challenge of Remaining in Sync with Global Demand}

The sporting goods industry is constrained by the lack of investment in R\&D and shortage of proper scientific and technological infrastructure, as a result of which it suffers from low levels of innovation, competitiveness, and productivity. The country is currently ranked 118 out of 142 countries on the 2011/12 global competitiveness index. This indicates that most sectors have failed to keep up with global trends, innovations in product development, new designs, modern manufacturing techniques, and diversification into growing product lines. 
The industry's lack of competitiveness is also due to inadequate specialized factors such as modern technology, training institutes, and research centers. In comparison to major players in the global sporting goods market such as China, India, and Thailand, Pakistan is far behind in terms of technology and modern production processes. The introduction of new technologies, production methods, and materials wiped out certain product categories (tennis, badminton, and squash rackets) from Pakistan's product profile and now threatens its core product-inflatable balls.

Among our respondents, small firms felt that the most serious obstacle to their growth was their limited ability to innovate and diversify their product range. As mentioned before, in comparison to international standards, the industry still uses only a basic level of production technology involving cut and stitch (balls, bags, and apparel) and relies primarily on imported inputs. The firms that have been able to move onto a higher growth trajectory and doubled in size over the last ten years are those that have innovated and effectively diversified their product range. According to them, the global sporting goods market is now about "lifestyle" and 95 percent of the market demand is for sporting accessories and apparel. Firms that made a timely and strategic move toward manufacturing a wider range of products in line with changing patterns of global demand have thus grown significantly (see Box 2).

For example, a medium-size to large firm that used to make soccer balls for a major international brand diversified into apparel in a joint venture with a Dutch firm. Recently, the firm has also begun manufacturing sports shoes in association with an Italian firm that is also a potential client. The firm has been able to establish links with sports clubs and retailers in Australia and supplies products to them directly. This is a niche market, they report, with a low volume but very high margins. Their strategy in shoe manufacturing is to import the raw material first, experiment with production for the local market, and then gradually bring the quality up to international export standards.

The essential ingredients for product diversification include investing in modern machinery and technology, good dyeing and knitting facilities, and firm-level R\&D. Given the trends in global demand toward sporting apparel, there is a dire need for ancillary industries (such as polyester and dyeing/knitting firms) to be developed. As in the example mentioned above, partnerships and joint ventures with foreign brands and investors have led to diversification and also been a source of finance and knowledge and technology spillovers. 


\section{Box 2: The case of Forward Sports: Linkages with the global market}

Forward was started in 1990 with an initial capital outlay of PRs 1.5 million. The firm had an edge from the start: its CEO had worked at his father's firm, Capital Sports, for 15 years prior to starting Forward. Capital Sports had been manufacturing footballs for Adidas since 1975. An established client, Adidas continued working with both Capital Sports and Forward Sports after the split. Initially, Forward produced hand-stitched footballs. In 1998, as a consequence of growing concern about child labor, most foreign brands exited the Pakistani market. Forward starting moving toward technology-based production so as to become less dependent on labor.

It invested steadily in foreign machinery and developed local machinery where possible, realizing that labor laws were making it harder to maintain a competitive edge in hand-stitched balls. In 2003, the international market demand switched to machine-stitched and thermo-bonded balls. In 2007, Forward followed suit, becoming the first and only firm in Sialkot to produce thermo-bonded balls. In 2011, they added machine-stitched balls to their product range. Currently, Forward produces all three categories: 250,000 machine-stitched balls, 75,000 thermo-bonded balls, and 600,000 hand-stitched balls a month.

The firm has an established in-house R\&D process, which reverse-engineers all imported machines as soon as they arrive, with the result that manufacturing is almost entirely on locally built machines. It has also identified key parameters of performance and quality and moved to 3D visualization and virtual sampling. This enables it to enhance whichever parameter the client requires and produce it for sampling in just four weeks.

The key to its success in the industry has been the firm's innovative and forward-looking behavior. It has constantly pre-empted market demand, driven by a clear understanding of product and technology lifecycles. As it approaches the point where a particular product or production technique is declining, the firm innovates and moves onto new products and techniques. Its patronage by Adidas as a main client is a constant source of knowledge and technology spillovers, and the established demand for the firm's product allows it the margins needed to invest in labor, machinery and, most important, R\&D. These investments, in turn, ensure that the firm is able to retain Adidas football manufacturing and remain part of the global changes in technology rather than being left behind.

Hockey manufacturers in Sialkot have, with the help of a foreign consultant, established links with local universities for the purpose of product innovation. Collaboration with the National University of Sciences and Technology and the Ghulam Ishaq Khan Institute of Engineering Sciences and Technology has helped resolve many of their problems such as new resin development and breakage issues. Interestingly, prior to this, 
they were not even aware that these universities had the required laboratories and facilities to help with product development. This underscores the critical need to establish industry-academia linkages, which is currently limited to just a few cases.

Finally, there are many advantages to being a major supplier for an international brand. These range from constant upgrading and investments in labor training programs, the introduction of lean manufacturing processes, logistics training, and environmental training to conducting audits and measuring performance indicators. The following statement by a firm owner/manager encapsulates the importance of working closely with big brands:

Success is entirely dependent on relationships with the brand. Any firm that is able to cling on to a major brand grows phenomenally.

\subsubsection{Branding: A Viable Option?}

Most sporting goods firms, including those we interviewed, manufacture products either directly or indirectly for a particular international brand. Although there are huge margins to be made in establishing one's own brand name internationally, the perceived costs of doing so are exorbitant. Branding is considered a completely different ballgame that requires a very different set of skills and resources from what the majority of established firms in Sialkot have. Our respondents felt that the industry's strength or comparative advantage lay squarely in manufacturing and not in branding, which explains their reluctance to move toward that objective.

The sector has made little effort to promote the establishment of a local market. The negligible market for sporting goods that currently exists in the country is quite unsophisticated and has been taken over by low-quality, low priced Chinese products. None of the firms interviewed were selling in the domestic market, which, they observed, the proliferation of fake brand names and low-quality goods had made very difficult for domestic producers to penetrate.

\subsubsection{Institutions and Infrastructure}

With no competition laws governing Pakistan's manufacturing sector, predatory pricing is common. Firms in this sector engage in stiff competition with one another and regularly resort to price wars to attract 
buyers; in a significant number of cases, the undercutting has been so substantial that they could barely recoup their production costs. Such predatory tactics are highly damaging and have contributed to the overall decline of the sporting goods sector.

Respondents offered contrasting opinions on the role and effectiveness of industry associations. Some felt there was inadequate information sharing among firms while weak contract enforcement meant they had failed to export jointly in order to meet large import orders. Many firms thought that the negative nature of competition in the industry (severe price-cutting and the active poaching of customers) would hurt its long-term development.

In sharp contrast to this is the Hockey Association, which has a membership of about 20 firms. The association's platform is used effectively to benefit all its members through joint activities such as purchasing imported raw material, sponsoring national hockey players, fixing labor rates, and employing lawyers for legal representation. The central reason for this cooperation is that these firms do not compete with each other-the international market and the brands for which they manufacture are large enough to absorb many players without any threat of market stealing.

Few public sector institutions exist to support the sporting goods industry. Quality testing and certification facilities are limited and the capacities of independent $R \& D$, training, and vocational institutes are often outdated. According to most of our respondents, the government had collected billions of rupees from exporters through the Export Development Fund, but spent little to upgrade technological know-how or develop technology for the sporting goods sector.

A pertinent example of the inefficiency of government departments in supporting innovation and technology in this sector concerns the mechanization of football manufacturing. Our survey revealed that approximately 10 manufacturers had got together to work on producing a mechanized, composite-based football. They had asked the government for support and started work on the initiative with SMEDA; subsequently, PRs 187 million was approved for the project in 2004. However, due to a lapse in funding, no further progress was made, resulting in a huge loss to football manufacturers, in particular to SMEs, which lack the capacity or resources to invest in mechanization. 
Another major public sector initiative to promote innovation in the industry was the establishment of the Gujranwala Tools and Dye Moulding Centre. However, the machinery and tools it manufactures are, reportedly, outdated, poor-quality, and very expensive. As a consequence, most firms prefer to buy machines and tools from the private sector. The Sialkot Chamber of Commerce and Industries has repeatedly demanded that the management of the center be handed over to them.

Government departments, particularly customs, are seen as being extremely inefficient. There is no facility for tracing imports and EMS lacks the standard system employed by international courier firms that allows importers to trace their order and manage their production schedule accordingly. Although rent seeking by customs officials was identified as a problem, the more pressing issue highlighted was the sheer inefficiency and incompetence of officials.

The inadequate support provided by the public sector is coupled with policy uncertainty. So far, the government's policies for the sector have lacked focus because it does not know with which stakeholders to engage. From the sector's perspective, existing government policies such as customs regulations and duties are often unclear, a number of previous policies (such as that of gas disconnections without prior notice) have been inconsistent, and policies with regard to $R \& D$ and export rebates are not satisfactorily implemented. This lack of policy focus, clarity, and inconsistency has been counterproductive and inhibited the growth of firms and the development of the industry as a whole.

The government's failure to provide the industry with the requisite infrastructure has compelled the private sector in Sialkot to address this problem directly. Accordingly, the latter has established a dry port and international airport-both unprecedented examples of private sector cooperation and initiative to relieve infrastructural constraints.

\subsubsection{Energy Shortages}

Over the last couple of years, all firms across Pakistan, including those in Sialkot, have identified energy shortages as the most serious constraint to growth and productivity. This is evident from the various cost-of-doing-business surveys conducted periodically in the country. Although the continued energy crisis is a major constraint to firms in the sporting goods sector, our interviews did not focus specifically on this for two important reasons. First, the energy crisis, albeit a serious issue, has 
not been a chronic constraint to firm growth. We have focused exclusively on impediments to firm growth identified retrospectively since the inception of a firm; this particular impediment does not figure as an endemic issue over this long-term timeframe. Second, the cost-ofdoing-business surveys have already dealt with the energy issue in considerable detail, looking at its impact across sectors and firm size and estimating the effect on costs of production. Focusing on this constraint here would merely have repeated earlier findings.

\subsection{Conclusion}

Our focused study indicates that perhaps the foremost impediment to growth for small firms in the sporting goods sector is their inability to innovate and diversify their product range in accordance with changing patterns of world demand. Firms that are closely connected to large international brands have, on average, fared better and grown over time. Those that export through buying houses have tended to remain small. The availability of raw materials and credit, inadequate human capital, and labor rules and regulations are more of a binding constraint for smaller firms than for larger ones. The latter have access to technology, capital resources, and training because of their close links with international brands or the global value chain.

Better managerial skills and succession planning is also a major factor distinguishing high-performance firms from low performers. Firms that have been poorly or unprofessionally managed and fragmented into smaller units over generations have generally stagnated and eventually gone out of business. Smaller firms, which are less diversified, tend to engage in fiercer competition involving price wars to poach potential buyers or brands. This results in a low survival rate in the sector. In contrast, firms that have been able to innovate in production and diversify their product range face no such threat.

Finally, public sector interventions to promote innovation and technology have been unsuccessful. Conversely, Sialkot is a good example of coordination and cooperation by the private sector itself to provide infrastructure such as the dry port and airport. Additionally, the government's lack of policy direction and general policy uncertainty has not only impeded the growth of small firms, but also been a major obstacle to the growth and development of the overall sporting goods industry. 


\section{Policy Recommendations}

The fan and sporting goods industries provide an interesting comparison of the barriers to firm growth. The fan industry appears to be trapped by low profitability, poor-quality production, and an inability to access international markets. With the important exception of a few large firms, the sector is characterized by many small firms supplying a relatively unsophisticated domestic market and competing on price rather than product quality. Survival rates of firms in this sector are low and very few have been able to grow into successful medium to large enterprises.

Along with other factors, this vicious cycle is perpetuated by the lack of access to formal credit markets. This prohibits the financing of capital investments that could, potentially, enable small firms to move from their present low-level equilibrium onto a higher growth trajectory. Even the most persevering and enterprising firms in the sector have made only limited inroads into products and markets that generate higher margins and profits. The fan sector, therefore, requires far more institutional support from the government in order to break out of this trap, and it is hard to visualize a scenario in which they might manage this independently of such support.

The sporting goods sector, on the other hand, is outward-oriented with most firms either supplying directly to major international brands or indirectly through buying houses. What limits firm growth in this sector is the degree of product diversification and innovation, which, from the interviews we conducted, seems to depend largely on whether a firm is a direct supplier to a major brand.

In terms of government support to the sector, Sialkot is an exceptional case of the private provision of infrastructure. The private sector in Sialkot has cooperated successfully to finance the development of a dry port and international airport. In addition, it has sought financing through its major buyers-foreign brands-for labor training and product development purposes. Nonetheless, it will be difficult for these firms to remain competitive internationally if they continue to shoulder the burden of infrastructural development without support from the public sector. The role of government policy in providing infrastructure and facilitating product development and innovation, therefore, remains key. 
This section draws on the case study analysis to identify areas in which the government can potentially intervene to increase the productivity of smaller firms and improve their growth prospects.

\subsection{Crosscutting Issues and Policy Interventions}

The policy interventions below are common to both industries.

\subsubsection{Weak Contract Enforcement}

Weak contract enforcement results in many problems that can severely impede firm growth. There is a lack of trust evident in the system, which prevents the formation of successful partnerships and reduces opportunities for businesses to expand beyond a certain point.

In order to address this, the government must aim to improve the functioning of the lower courts, enabling them to enforce contracts. It should also strengthen alternative dispute settlement mechanisms. Finally, the role and credibility of the police-as the first point of contact with the private sector-must improve significantly. These institutions need to work effectively and in tandem in order to make commercial arbitration quick and transparent.

\subsubsection{Limited RED}

The study shows that both sectors operate under the technology curve. The fan industry's output is of low quality and design and has poor electrical efficiency. The sporting goods sector has, with a few exceptions, lost its global position in the rackets industry and is now fast losing its position in footballs as it fails to keep up with changing technology and products. Firms in both sectors consistently supply products for which there is declining global demand.

In order to address this issue, the government needs to provide an environment that is more conducive to investing in technology. Local research institutions should be strengthened to work closely with the industry. Public sector universities' research grants should be linked to the needs of the local industry so that the latter can benefit from innovative research. Agencies such as SMEDA and the Technology Upgradation and Skill Development Company (TUSDEC) should help link these sectors to the best research institutions globally to help induce technology. Technology development incubators could be developed as public-private partnerships to work on newer production methods, technologies, and products. We 
would strongly suggest that the government fund or facilitate privately managed initiatives as government-managed setups tend to suffer from lack of ownership dynamism and lead to progress that is too slow to be useful.

\subsubsection{Simplification of the Tax Regime}

Corruption has been identified as one of the most serious obstacles to firm growth. It generally stems from rent seeking by government officials and creates a perverse incentive for businesses to remain small and informal. An interesting consensus to emerge from our case studies was that firms said they wanted to operate in an environment where all firms paid their full tax liability and reneging firms did not have an unfair advantage. For this, we propose instituting a simplified tax system that requires minimal contact with public sector offices and allows firms to calculate and pay their tax liabilities easily and quickly. The current tax regime for exports could be used as a potential model.

\subsubsection{Energy Shortages}

Although we have already explained why energy shortages are not an endemic barrier to firm productivity across these sectors (Section 5.2.8), chronic energy shortages do have a significant impact on the future growth potential of firms across sectors.

The current tariffs are not industry-friendly: the industry winds up subsidizing the cost of electricity for domestic and commercial users, whereas, internationally the practice is the reverse. Electricity tariffs keep increasing in arrears, with instances where firms have had to pay the increased cost of electricity of the past six to nine months. These ex-post tariff changes make it difficult to carry out appropriate business costings. In order to address the issue, the government needs to resolve the energy crisis and rationalize power tariffs. In the interim, further research is required on cost-effective coping mechanisms that would allow firms to remain competitive internationally.

\subsubsection{Availability of Credit}

Credit rationing for SMEs emerges due to asymmetric information stemming from their limited capacity to provide reliable financial information and collateral. Small firms, in particular, do not have the capacity to comply with banks' documentation requirements. The cost of finance in terms of the high rate of interest has also been reported as a critical issue impeding access to credit. 
Policy suggestions that could, potentially, improve credit disbursement to SMEs include encouraging and introducing productand program-based lending at subsidized, single-digit mark-up rates with flexible repayment schedules. Moreover, the credit application process could be simplified to reduce red tape and allow alternative forms of collateral to be accepted for SMEs.

\subsection{The Fan Industry}

While some of the key impediments to firm growth in the fan industry could be resolved efficiently through the market mechanism, others will have to be addressed over the medium to long term and may require a certain degree of government intervention. These are discussed below.

\subsubsection{Low Barriers to Entry and Substandard Product Quality}

Extremely low barriers to entry in the fan industry have resulted in a large number of very small manufacturers producing, on average, very low-quality fans. Cutthroat price competition in the domestic market tends to generate a perverse incentive for producers to minimize cost at the expense of quality. This lack of quality filters through to the export market, making it costlier and far more difficult for the industry to meet international quality standards and compliance requirements. A related issue is the absence of standardization for common parts in fan manufacturing: this precludes the development of a support industry, which could lead to economies of scale.

The government needs to strengthen the capacity and transparency of the Pakistan Standards and Quality Control Authority to develop a consumer watchdog that periodically rates the quality parameters of fan manufacturers. The rating system should list the topquality fans based on their reliability, energy consumption, design, and overall quality. Introducing such a system may initially force some lowquality manufacturers to close down, but it will also open up space for progressive and quality-conscious manufacturers. It will also increase the incentive to invest in better technology and management systems.

Rationalizing the industry might also lessen price competition in local markets and thus increase the average firm's return on investment. Moreover, strictly enforcing local standards for both products and parts will significantly improve the quality of Pakistani fans, reduce costs due to scale economies, and make it easier for the industry to meet export requirements. 


\subsubsection{Limited Knowledge and Management Skills}

Much of the industry is characterized by low levels of literacy among business owners and poor management skills in areas such as succession planning and delegation. Both factors result in basic shortcomings such as poor account keeping, lack of capacity and confidence to export, limited expansion and diversification of business, and problems in dealing with service providers, e.g., commercial banks.

The government needs to help create opportunities for the systematic training of owners. Training courses in business management, strategy, record keeping, export procedures, banking procedures, succession planning, and consumer rights could be held in Gujrat jointly or individually by government bodies such as the National Productivity Organization, Engineering Development Board, Trade Development Authority of Pakistan (TDAP), and SMEDA. Such courses should be provided on a cost basis to ensure that firm owners participate. The organization providing the course should also continue to monitor its participants and provide support to those who wish to implement the changes they have learned.

\subsubsection{Seasonal Production and the Number of Skilled Workers}

Seasonal production in the fan industry has resulted in an outflow of skilled labor and created a shortage of trained workers, especially at the level of supervisor and factory floor manager. In order to address this issue, the government needs to work with PEFMA to initiate training programs for these particular skill levels (process supervisors and factory managers) through the Technical Education and Vocational Training Authority (TEVTA). Additionally, capacity-building programs will need to have a rapid impact on firms' capacity to export quickly in order for them to maintain production throughout the year. In doing so, TDAP should provide information on markets with opposite weather cycles to Pakistan, ensuring consistent demand throughout the year. Facilitating and funding privately owned and managed centers would help firms benefit from greater dynamism.

\subsubsection{Access to International Markets}

Many firms lack the information and confidence needed to export, which stems from unclearly stipulated export requirements and the counterproductive role played by commercial exporters. Areas for policy 
intervention include the provision of an export enquiry point for small or new exporters, which would consolidate and facilitate all the financial and logistical information required to export. In addition, trade roadshows could be arranged to market products in potential export destinations, particularly those with opposite weather cycles. In arranging road-shows, the fan sector could potentially collaborate with the furniture sector, which is slightly more developed; fans could then be marketed as a higher-value decor item along with home furnishings.

\subsection{The Sporting Goods Industry}

The policy interventions discussed below address the specific issues of the sporting goods sector.

\subsubsection{Lack of Innovation and Product Diversification}

The sporting goods industry is outward-oriented and thus far more dynamic than the fan industry. However, in order to keep pace with changing demand patterns worldwide, the industry must continuously improve and invest in R\&D. With some exceptions, most producers in Pakistan are reactive rather than proactive with regard to product demand and technology changes. The resultant lack of diversification in their export base limits growth opportunities and reduces their world market share over time.

An innovation and design center that works jointly with the sporting goods industry and external research institutions would help bridge the knowledge and technology gap. The private sector has already initiated a technology center and invested in creating the infrastructure and procuring the equipment needed. However, the deliverables of this project on the government side are still missing.

\subsubsection{Inadequacy of Ancillary Industry}

The sporting goods industry depends heavily on imported inputs, which means that small firms are left struggling due to the limited and uncertain availability and the high cost of importing these inputs. For larger firms, which import materials directly, availability is less problematic as they keep an inventory. However, this translates into higher costs with six to eight months of inventory tying up funds. The input and support industry is, therefore, a major concern for almost the entire value-added sector of Pakistan. The government needs to introduce 
appropriate incentives so that large-scale manufacturing in key inputs (such as latex and composites) is established within the country.

\subsection{Areas of Further Research}

Cost-of-doing-business surveys identify the main crosscutting constraints to firm productivity and industrial development. Their very large samples and wide range of industries mean that they are unable to delve deeper into the firm-level constraints identified. Also, such studies are based on cross-sectional data reflecting the perception of firms at a particular point in time. Thus, they are unable to capture the historic and endemic issues that have resulted in firm success or failure.

The methodology we have adopted was an attempt to fill this gap in research on firm-level constraints. By focusing on just two, but very different, clusters and restricting the sample to a relatively small number of firms, we were able to adopt a more detailed, retrospective method of extracting information on the specific ingredients of firm success or failure. This case study method has enabled a richer and deeper insight into the chronic problems inhibiting firm growth.

Although we have identified a number of areas that need policy attention, further research is needed to fine-tune specific, implementable policy interventions to counter the inherent inefficiency and weakness of the public sector. Broadly, the guiding principle behind these interventions should be to incentivize and facilitate the private sector. We suggest this policy design-focused research be undertaken in collaboration with the industry.

An interesting aspect that emerged from our case studies concerned the very divergent characteristics and trajectories of two geographically proximate clusters. It would be interesting to identify the factors that have led to the clusters operating in apparent isolation without the expected spillovers that the literature on industry and economic geography predicts.

The study could also be easily expanded in scale and scope to additional sectors so that a more comprehensive picture of firm constraints is established, particularly for industries or clusters categorized as "sunrise" sectors with potential that is not being fully exploited. 


\section{References}

Angelini, P., \& Generale, A. (2008). On the evolution of firm size distributions. American Economic Review, 98, 426-438.

Bari, Faisal, Ali Cheema and Ehsan-ul-Haque. (2005). SME Development in Pakistan: Analyzing the Constraints to Growth (Working Paper). Manila: Asian Development Bank.

Competitiveness Support Fund. (2010). The state of Pakistan's competitiveness report 2010-2011. Islamabad: Author.

Hussain, S. T., Khan, U., Malik, K. Z., \& Faheem, A. (2012). Constraints faced by industry in Punjab, Pakistan (Working paper). London: International Growth Centre.

Khan, U. (2011). Strategy for fan industry (Mimeo). Available from www.trtapakistan.com

Manes, E. (2009). Pakistan's investment climate: Laying the foundation for renewed growth (vol. 1). Washington, DC: World Bank.

Munir, K., \& Khan, U. (2011). SME cluster study: Fan industry in Gujrat and Gujranwala. Karachi: State Bank of Pakistan. Retrieved from http://www.sbp.org.pk/departments/ihfd/Sub-

Segment\%20Booklets/Fan\%20Industry\%20Report.pdf

Small and Medium Enterprise Development Authority. (2012). Sports goods sector strategy. Lahore: Author.

World Bank. (2007). Enterprise surveys: Pakistan country profile 2007. Available

http:/ / www.enterprisesurveys.org/ /media/GIAWB/Enterpris eSurveys/Documents/Profiles/English/Pakistan-2007.pdf

World Bank. (2014). Worldwide governance indicators | Data [Database]. Available at http://data.worldbank.org/datacatalog/worldwide-governance-indicators

Yang, J. S. (2011). Business environment perceptions in Afghanistan and Pakistan (Enterprise Note No. 27). Retrieved from http:/ /www3.weforum.org/docs/WEF_GlobalCompetitivenessR eport_2012-13.pdf 